\title{
Frutas para o mercado global
}

\author{
JOSEFA SALETE BARBOSA CAVALCANTI
}

$\mathrm{O}$

VALE DO SÃO FRANCISCO é, na atualidade, uma das regiões agrícolas mais dinâmicas do Nordeste brasileiro. Esse lugar de destaque na economia deve-se originalmente ao forte apoio recebido do Estado, a partir dos anos 70, por meio de seus projetos de desenvolvimento referentes à introdução de esquemas de irrigação estimulados pelo potencial hidroelétrico oferecido pela construção da barragem de Sobradinho e às características de sua inserção nos mercados interno e internacional.

Entretanto, apesar de algumas experiências anteriores com agricultura irrigada, foi somente a partir da segunda metade da década de 80 que a região tornou-se visível como um locus do planejamento nacional, com a constituição da Codevasf - que tornou-se a Instituição responsável pela coordenação do seu desenvolvimento. Desde o fim dos anos 80 o vale do São Francisco passou a se distinguir por sua produção e pelos vínculos que estabelece com o mercado global ao produzir frutas com o padrão de qualidade esperado pelos compradores e consumidores internacionais. O impulso desses vínculos com o mercado é dado pelo crescimento da produção para exportação em dois dos seus principais municípios: Petrolina-PE e Juazeiro-BA. Uva e manga tornaram-se frutas especiais pelo espaço de comercialização conquistado: $20 \%$ da produção de cada uma delas são vendidos fora do Brasil, para a Europa e os Estados Unidos. Ressalta-se ainda que a produção do vale encontra lugar especial na seleção de frutas feita por cadeias transnacionais de supermercados que requerem produtos tipo exportação. Deve-se, pois, atentar para o fato de que as frutas passam a ser selecionadas de acordo com as exigências dos compradores ou consumidores a que se desti$\operatorname{nam}(1)$.

Como resultado dessa relação com setores nobres do mercado e do crescimento da produção, os dois municípios, Petrolina (PE) e Juazeiro (BA), passaram a ser área de atração de migrantes vindos de várias partes do Nordeste e também de outras regiões do país como Sul e Sudeste, por exemplo. Chegaram como colonos, trabalhadores assalariados ou empresários na esperança de encontrar na produção frutícola a prosperidade que buscavam. Trouxeram consigo traços da sua cultura, do seu modo de trabalhar e viver o dia a dia. Como resultado, a região é formada por representantes da população brasileira de distintas características étnicas: são nordestinos, paulistas, italianos, japoneses, entre outros, que se encontram no cotidiano das principais cidades da região. Alguns deles ainda se deslocam, oportunamente, a outros centros do mundo para acompanhar as novidades em sua área de atuação, ou recebem com freqüência visitantes e especialistas de outros países que chegam ao Nordeste para conhecê-lo, nele trabalhar ou estabelecer negócios. 
As cidades crescem (IBGE, 1991) como pólos de atração; transformam-se os seus espaços: transeuntes que circulam usando telefones celulares, adentrando em lojas que vendem fax, freqüentando cursos de línguas estrangeiras, adquirindo antenas parabólicas, carros importados, demonstram a riqueza e o caráter cosmopolita daquelas cidades do sertão nordestino e os distintos tipos dos seus moradores. Ao mesmo tempo, multiplica-se o número de organizações e associações que garantem os novos espaços de sociabilidade.

Por outro lado, observa-se que a paisagem rural vai sendo paulatinamente modificada. Produtores e trabalhadores tendem a viver nas áreas urbanas e trabalhar nos campos. Nas cidades vivem as famílias dos produtores que administram as suas empresas e os trabalhadores que buscam emprego e meios ágeis de deslocamento até os seus pontos de trabalho nos lotes de colonos e nas agroindustrias. Nos campos crescem, além das agroindústrias, os galpões de empacotamento, as câmaras para refrigeração de frutas, os alojamentos para os trabalhadores (Vergolino \& Vergolino, 1995) e pequenas casas para as famílias que ficam no campo durante o dia e regressam, à noite, aos seus lares nas cidades. Automóveis e caminhões, comuns ou com câmaras frigoríficas, trafegam continuamente entre as áreas. A esses aspectos externos da região devem ser consideradas as mudanças que ocorrem na organização da produção e do trabalho em suas unidades produtivas.

O grande motivo dessas transformações, as frutas, caracterizam algumas das relações dos habitantes da região com o resto do mundo. Para lidar com a nova situação, os diferentes atores sociais desenvolvem estratégias que visam a tornar competitivos os seus produtos vis à vis os novos contornos do mercado global.

\section{Globalização e novas regiões produtivas}

Alguns pressupostos orientam este trabalho:

- a globalização da economia interfere em alguns setores produtivos de modo específico, a exemplo da agricultura (Bonnano et al, 1994), acentuando a interdependência mundial;

- a agricultura é um setor que, embora permaneça como parte da natureza (Marsden et al., 1996), na atualidade é fortemente orientada por regulações externas que controlam o que, quando, onde e como produzir. O controle externo sobre o tipo de produto que deve ir aos mercados interfere, assim, nas decisões que orientam o processo produtivo e nas estratégias utilizadas pelos produtores para garantir a competitividade dos seus produtos. Tais estratégias repercutem nos processos de trabalho e nas formas de controle sobre os trabalhadores; esse fato é particularmente verdadeiro nos casos de produtos que se destinam aos mercados internacionais (Friedland, 1994);

- o controle externo sobre a produção agrícola é realizado segundo duas 
perspectivas: uma, definida pelos interesses e demandas dos consumidores dos países de destino da mercadoria e imposta pelo estabelecimento de limites ou fronteiras de mercados; outra, decorrente desta, imposta pelo requerimento de condições locais adequadas de produção, sejam elas ambientais, sócio-econômicas ou políticas para citar algumas e, em especial, uma combinação eficiente de uso e administração de recursos humanos que garanta o trabalho necessário à produção de acordo com os padrões de qualidade previamente definidos.

Os vínculos de regiões produtivas particulares (Sabel, 1994) com a economia global adquirem características especiais no contexto da globalização. A globalização da atividade econômica é "uma forma mais complexa de integração funcional entre atividades econômicas internacionalmente dispersas" (Dikens, 1992:1, apud Spybey, 1996:77). Ao mesmo tempo, dá origem a uma divisão internacional do trabalho, na qual "as pessoas no mundo foram levadas à produção de bens intercambiáveis internacionalmente" (Spybey, 1996:77). Contribui, então, em nível local, para a transformação das relações de trabalho, da divisão sexual do trabalho, das características da gestão das unidades produtivas, da participação dos trabalhadores e das ações dos Estados. Os fundamentos da economia global, como ilustra Spybey (1996:86), “... é um arranjo para o governo de partes definidas do território que contêm populações designadas; os governos desses Estados estabelecem as restrições básicas para a passagem de bens e serviços através das fronteiras nacionais e a corporação transnacional é um arranjo para juntar a rede dos lugares da produção, fontes de trabalho e espaços de mercado para fazer o melhor uso das oportunidades econômicas através do sistema do Estado-nação".

Como analisado por Marsden \& Arce (1995) e Marsden et al. (1996), o controle de qualidade dos alimentos, do meio ambiente e do trabalho apresentase, na atualidade, como um mecanismo que visa garantir à agricultura de regiões particulares a competitividade e sustentabilidade vis à vis o poder das cadeias transnacionais de alimentos. Por outro lado, para responder aos desafios de uma economia que se constitui de acordo com tais exigências, o controle do conbecimento, de saberes é um fator essencial para o sucesso de determinadas categorias sociais, no seu lidar com agentes externos ao seu dia a dia.

\section{Globalização, trabalho e poder em regiões particulares}

A vinculação da produção agrícola às cadeias transnacionais de alimentos é um fato que se fundamenta em poder, é político (Friedmann, 1994); assim, relações hierarquizadas permeiam as ações dos sujeitos que têm o domínio do conhecimento de algumas de suas partes. Mas, não apenas esse conhecimento caracteriza tais sujeitos e os seus saberes; cada um deles tem a sua própria trajetória social e foi socializado de acordo com uma cultura que orienta as suas ações e tende a orientar a forma como toma suas decisões. Assim, aqueles que participam da rede de relações que marcam a economia globalizada se diferenciam 
quanto às suas origens e aos seus modos de inserção nos diferentes momentos da produção e circulação de bens. As distintas formas de sua participação ora reforçam o poder do seu conhecimento, ora o desqualificam frente a outros participantes da rede. As estratégias utilizadas para legitimar-se nesse contexto fazem parte de um patrimônio passível de ser transmitido de acordo com as regras que garantem as relações entre gerações, dos que participam de uma rede de parentesco; entre companheiros de trabalho, dos que formam as diferentes categorias de trabalhadores de uma empresa; entre os que se identificam como membros de um grupo étnico; entre os que guardam uma possível identificação de gênero, para citar alguns dos casos aqui analisados.

Com as idéias delineadas tem-se como objetivo propor algumas questões que surgem no dia a dia de um projeto integrado de pesquisa (2), quando o domínio do conhecimento de como lidar com as exigências dos mercados internacionais quanto à qualidade dos produtos apresenta-se, a cada momento, de acordo com as avaliações de colonos, empresários, exportadores e trabalhadores, como estímulos ou limitações ao sucesso do empreendimento da produção frutícola no vale do São Francisco do Nordeste brasileiro.

\section{A integração do vale do São Francisco ao mercado global}

A implementação de novas áreas de produção agrícola no sertão pernambucano foi estimulada pela presença de vários projetos de irrigação executados na região (3). A organização do novo espaço (conforme o mapa apresentado) incluiu áreas para colonos e áreas para empresas. As áreas para colonos foram inicialmente destinadas àqueles que lá já trabalhavam, como proprietários das terras desapropriadas para dar espaço aos esquemas de irrigação, ou a outros trabalhadores rurais previamente selecionados.

Um dos projetos implementados - o Nilo Coelho, por exemplo - conta com 1.442 colonos, 169 empresas e 110 lotes para técnicos agrícolas (Codevasf, 1996) e ofereceu 1.500 lotes originais; 700 destinados a ex-proprietários, dos quais $60 \%$ repassaram a outros os lotes recebidos. Há indícios de que apenas $10 \%$ dos seus primeiros colonos continuem a atuar na região. A seleção inicial dos que receberiam os lotes, e a desistência de muitos deles, originou um processo informal de concessão de terras a pessoas que não administravam elas próprias os seus lotes: eram irmãs, esposas de colonos, por exemplo, que emprestavam os seus nomes para a obtenção de mais um lote. Por outro lado, houve a possibilidade de repasses, pelos quais vários migrantes tiveram acesso às terras irrigadas do vale, a exemplo de agricultores de origem japonesa, de vários profissionais com nível superior de escolaridade que paulatinamente foram se estabelecendo na área, contribuindo para mudanças nas práticas de produção e gestão dos empreendimentos locais. Alguns ajustes estão sendo procedidos pela Codevasf para resolver a questão de colonos não-aptos. Entre eles, o estabelecimento de critérios de seleção, que incluem itens como existir força de trabalho familiar, haver 


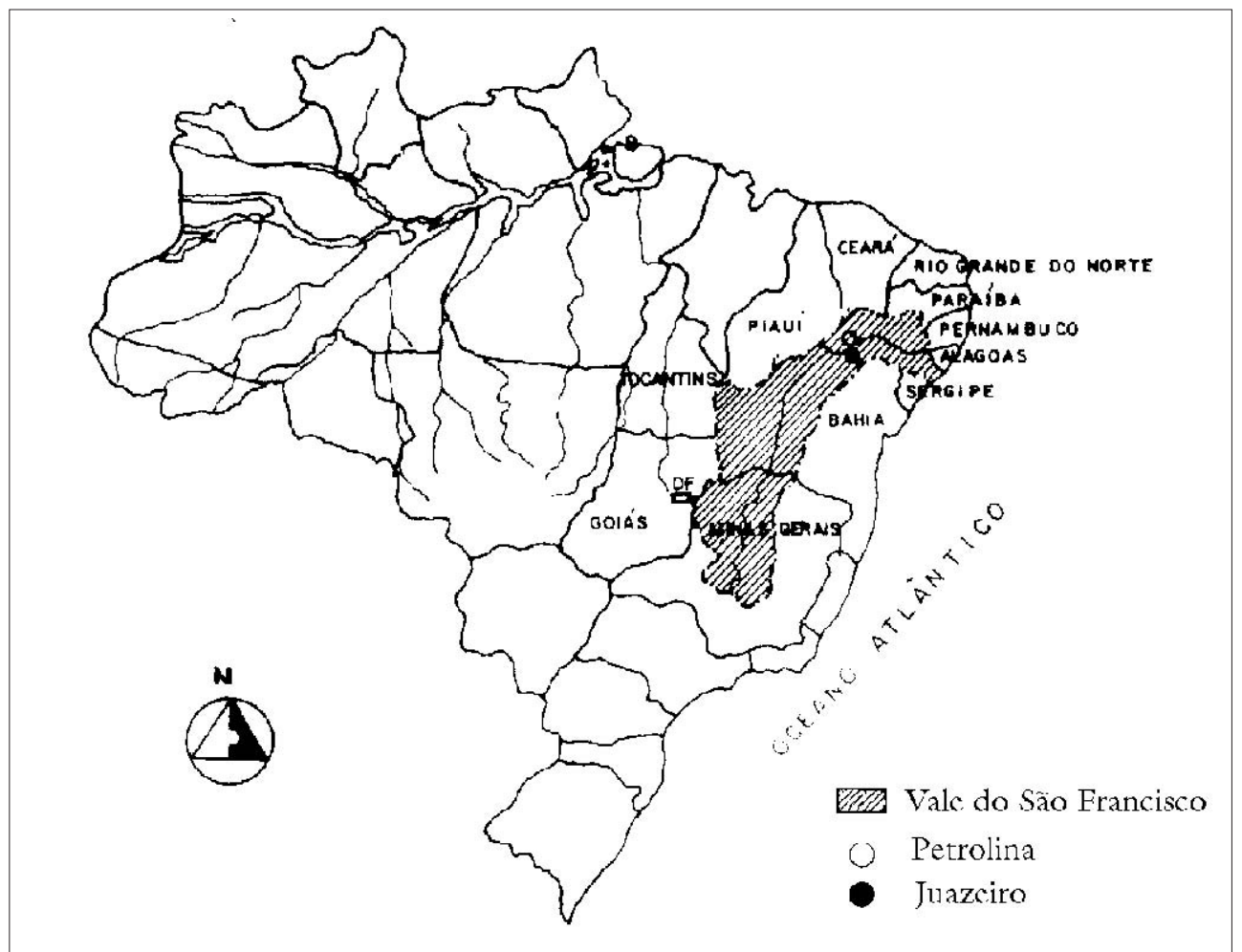

Vale do São Francisco - Nordeste do Brasil

Experiência recente refere-se à concessão de lotes a técnicos em Ciências Agrárias para que possam trabalhar em estabelecimentos próprios e, segundo a expectativa, dinamizar uma das áreas de expansão do perímetro irrigado. Os colonos que recebiam um lote de até 6 há à época da implantação dos primeiros projetos, poderiam então receber legalmente até 12 ha. Deveriam praticar a policultura, enquanto das áreas destinadas às empresas esperava-se especialização na produção de culturas como cebola, tomate ou melancia para os mercados regional e nacional. Posteriormente, porém, a produção do vale do São Francisco foi se transformando com a introdução de novos sistemas produtivos fundamentados na fruticultura de manga e uva principalmente, levadas a outros mercados, além das fronteiras brasileiras. As crises nos sistemas de produção que dominaram até os anos 80 e as possibilidades abertas com o processo de globalização e seus desdobramentos na agricultura, associadas às mudanças nos padrões alimentares nos chamados países do Norte, sensibilizaram colonos e empresários a produzir para a exportação. Assim, frutas como uva e manga destacam-se enquanto mercadorias orientadas prioritariamente para os mercados 
internacionais, ainda que mantenham fortes vínculos com os mercados regionais e nacional. A produção de frutas destinada aos grandes centros urbanos do país e à exportação é uma das atividades mais rentáveis do vale (Bloch, 1996:35). Entretanto, devido às dificuldades operacionais e aos controles sobre a produção destinada à exportação, ou quando a demanda interna se torna mais rentável, alguns produtores optam pelo mercado nacional, embora a quantidade exportada de manga e uva tenha crescido nos últimos anos, como pode ser visualizado nos quadros apresentados no final do texto.

As características da inserção do vale do São Francisco entre as regiões que produzem frutas exóticas para os chamados países do Norte já foram analisadas em outros trabalhos (Cavalcanti, 1995; Cavalcanti \& Ferreira Irmão, 1995). Aqui pretende-se, a partir de caracterização prévia dos distintos atores que fazem parte do processo de produção frutícola do Vale do São Francisco, definir como, na busca da qualidade em seus níveis distintos, várias categorias sociais respondem aos desafios que se lhes apresentam. Toma-se como casos exemplares produtores e exportadores para, a partir da análise de situações do seu cotidiano, compreender os mecanismos da produção e transmissão do conhecimento, especialmente nos aspectos relativos à gestão das suas atividades.

Em uma nova situação, é interessante observar a preocupação com a qualidade quase sempre demonstrada a partir de certa desconfiança quanto ao controle exercido por um indivíduo sobre o conhecimento e as ações do outro: produtores são controlados pela inspeção do tipo de mercadorias que oferecem; trabalhadores são controlados pelo tipo de trabalho que realizam; produtores e exportadores, pelas regulações que definem a qualidade do produto, as quais consideram cor e formato (peso, tamanho) das frutas e as condições gerais do processo de produção. Nesse contexto, o valor agregado aos produtos (polimento das frutas, tipos de embalagem, rótulos são valores que ultrapassam a produção como tradicionalmente considerada) foge ao controle direto de alguns atores sociais e os deixam vulneráveis frente aos demais.

A qualidade das mercadorias tende a se impor de forma objetiva pelas normas que regulam a produção e sua apresentação final; no entanto, as normas que regem as relações de trabalho e o controle ambiental são flexípeis, assegurando a margem de manobra dos agentes sociais frente aos desafios da competitividade no modo de lidar com os mercados.

\section{Os desafios à competitividade da fruticultura}

A fruticultura é, na atualidade, um dos segmentos mais dinâmicos e competitivos do setor agrícola. No Nordeste, foi incluída no item renda proveniente da moderna agricultura de exportação, no cálculo do PIB da região. Alguns dos produtos vêm experimentando significativo crescimento em suas exportações, dentre eles uva, manga, melão e abacaxi, além de sucos processados e castanhas de caju, que também já representam considerável parcela das exportações nos estados do Ceará, Rio Grande do Norte e Paraíba. Tais produtos sobressaem por 
sua potencialidade produtiva na região e pelo incremento do seu consumo nos mercados internacionais.

Ademais, são produtos que apresentam alternativas de integração competitiva no comércio internacional, diferentemente das formas de dependência dos produtos tradicionais do Nordeste, a exemplo da cana de açúcar. Os números atestam o dinamismo desse segmento da agricultura de exportação. Essa "produção agro-industrial associada à irrigação, instalada tanto no vale do São Francisco (BA e PE) como no vale do Açu (Rio Grande do Norte) também desenvolve importantes articulações econômicas extra-regionais, em particular no que se refere ao destino de sua produção" (Araújo, 1994:143).

Esses setores mais direcionados à exportação tendem a se ajustar a requisitos e cuidados especiais quanto aos aspectos fitossanitários e de apresentação de produtos os quais, nesse contexto, podem implicar novos tipos de exploração do trabalho, que surgem segundo as novas formas de gestão, flexibilização do trabalho e estabelecimento de novas parcerias, pré-requisitos para a competitividade nas condições atuais de mercado.

É importante assinalar que a adaptação da produção aos novos ritmos e espaços que se ampliam com a abertura de mercados e com os novos acordos de integração regional entre países, requer relações entre capital e trabalho redefinidas; isso significa uma participação coletiva dos distintos atores nas diferentes fases do processo produtivo e, ainda mais, uma responsabilidade coletiva na qualidade final do produto. Perseguir um padrão de qualidade significa coordenar e organizar eficientemente tempo, conbecimento, tecnologia e recursos humanos. Produtores e trabalhadores devem estar preparados para as novas práticas de gestão e outras tarefas especializadas agora requeridas.

A região estudada vem se destacando pela oferta de empregos (UFPE,1991) tendo crescido enquanto área de atração de trabalhadores, numa situação crítica de emigração que caracteriza a região Nordeste. Na segunda metade da década de 90 , a geração de novos empregos tem se revelado especialmente promissora no caso dos produtos destinados à exportação com impactos na divisão sexual do trabalho (Cavalcanti et al., 1996). As culturas predominantemente destinadas à exportação distinguem-se quanto ao uso do trabalho de homens e mulheres; a mão-de-obra preferencial na produção de mangas é masculina, e feminina na viticultura. A femininização do trabalho na viticultura caracteriza também a produção de uvas no Chile (Mendel, 1989), devido ao caráter artesanal da produção.

Quanto ao tamanho da força de trabalho ocupada na fruticultura, não existem dados objetivos; não há informações oficiais quanto ao número de trabalhadores que realmente atuam na fruticultura. Os números que constam dos relatórios oficiais variam e, certamente, são inferiores ao número real. Para a área de Petrolina e Juazeiro, por exemplo, a estimativa é de 20 mil a 30 mil trabalhadores diretamente vinculados à produção; já no setor de serviços, segundo indicam os relatórios da Codevasf (1996) o número de empregos indiretos tenderia 
a ser maior, mas também não há dados precisos sobre ele. As informações contidas nas RAIS do Ministério do Trabalho também não têm registrado com fidelidade todas as transformações ocorridas nessa área. As formas precárias de recrutamento e remuneração da mão-de-obra, bem como o incremento do trabalho necessário em certas fases da produção e colheita têm contribuído para a desproporcionalidade entre o número de contratos permanentes e o de temporários, estes últimos tanto podendo se referir a contratos formais quanto a informais (não-legalizados).

Nessas condições, são igualmente precárias as formas de participação política dos trabalhadores. Como analisado por Bendini \& Cavalcanti (1996), a fraca organização dos sindicatos reflete tal situação, distinguindo os trabalhadores do vale do São Francisco dos trabalhadores da fruticultura do Alto Valle Argentino, mais organizados e participativos. No vale do São Francisco, a primeira convenção coletiva de trabalho ocorreu em 1993, quando foi aprovado o piso salarial da categoria: um salário mínimo mais 10\%; quanto à fiscalização do cumprimento das normas, apenas em 1996 a região passou a contar com fiscais fixos do Ministério do Trabalho. Entretanto, a tendência é de que essa situação não venha a melhorar para os trabalhadores, face ao crescimento do número dos que procuram emprego (4), aos impactos da introdução de novas tecnologias e da restruturação produtiva, que tendem a reduzir o uso de mão-de-obra não-qualificada e a requerer trabalhadores que realizem tarefas múltiplas, em distintas fases da produção. Cita-se como exemplo, uma pequena empresa que realiza um trabalho de controle de qualidade, pelo do qual visa transformar a especificidade do trabalho que homens ou mulheres realizam. Tal exigência pode desequilibrar a atual divisão sexual do trabalho. Os trabalhos braçais são geralmente realizados por homens, como a preparação dos campos para produção, disseminação de agrotóxicos e tratos relativos à produção de manga. Os trabalhos relativos às várias etapas necessárias para tornar os cachos de uva prontos para serem levados ao mercado, tarefas que exigem técnicas adequadas de manuseio da uva segundo os padrões de qualidade previamente definidos - que se estendem do raleio até à embalagem - são, no mais das vezes, executados por mulheres. Mas tais mudanças na divisão sexual do trabalho não serão realizadas a curto prazo, seja pela resistência de homens e mulheres, pelo nível da pesquisa e variedade de uvas cultivadas na região, seja pelo baixo preço da mão-de-obra pago no vale, comparativamente a outras regiões vinícolas, como as do Chile, por exemplo.

Ressalta-se, entretanto, o fato de que mesmo na presença de abundante mão-de-obra, os produtores reclamam da falta de trabalhadores qualificados. Muitos desses trabalhadores qualificados, apesar da temporalidade dos seus contratos anteriores, são readmitidos pelas empresas porque se distinguiram, em algumas das fases da produção, no domínio do conhecimento de como produzir frutas com qualidade.

Outro aspecto que revela o impacto da globalização no controle sobre o trabalho naquela região é a presença de técnicos enviados pelo US Department of 
Agriculture (USDA-EUA) para inspecionar a forma como as regulações fitossanitárias que orientam a produção e embalagem das frutas são seguidas. A cada período de colheita, as frutas a serem exportadas para os Estados Unidos são cuidadosamente acompanhadas por um técnico do USDA, contratado pelos produtores do vale para atender às exigências dos compradores, e oferecer a garantia de que os produtos são encaminhados com qualidade aos consumidores daquele país.

\section{Sobre o controle de qualidade}

A objetividade quanto à qualidade da fruta a ser exportada é relativa. Há distintos tipos de exigências feitos por diferentes importadores das frutas do vale, como Estados Unidos e países da Europa quanto à qualidade das mangas e uvas que são exportadas para os seus países. Ao reclamarem dos rigores do controle de qualidade de suas mercadorias, os produtores estabelecem o contraste entre o que, segundo sua avaliação, é um produto de boa qualidade e o tipo de avaliação que rejeita esse mesmo produto, por não se enquadrar nos padrões requeridos Os produtores de acerola, por exemplo, estão há muito tempo esperando que a fruta venha a receber a aprovação do controle feito pelo Japão para a sua exportação. Ainda, há os produtores (empresários, colonos) que reclamam da falta de mão-de-obra qualificada para desenvolver os trabalhos, segundo os padrões requeridos pelos importadores. Os produtores têm usado mecanismos múltiplos para se ajustarem às exigências dos mercados, sejam internamente, em nível da organização da produção e controle sobre o trabalho, ou externamente, pelo desenvolvimento de estratégias defensivas e estabelecimento de alianças feitas para garantir a competitividade de sua produção nos mercados globais.

A criação da Valexport, em 1988, hoje com 35 empresas associadas é exemplo de como os produtores do vale se organizaram para assegurar sua participação nos mercados internacionais. Segundo um dos exportadores, no início das atividades, cada um pensava em exportar o seu produto, com o seu rótulo, para ganhar novos mercados. As dificuldades encontradas nas primeiras experiências demonstraram que eles somente seriam competitivos se pudessem oferecer maior quantidade de mercadorias, com a mesma qualidade requerida pelos compradores. Assim, resolveram constituir uma organização que possibilitasse a apresentação da produção do vale nas redes internacionais de alimentos. Passaram a utilizar um rótulo único para caracterizar sua marca, indicando a origem das mercadorias, embora o uso de rótulos próprios nem sempre seja possível, porque o mercado tem as suas regras e as corporações transnacionais formas específicas de marcar a qualidade dos seus produtos.

Tais controles visam ao atendimento de um padrão de qualidade e são contestados pelos trabalhadores, os quais reclamam do rigor com que seu trabalho é inspecionado. Os produtores, por sua vez, reclamam do tipo de controle exercido sobre a mercadoria que encaminham aos mercados estrangeiros. Portanto, há uma sucessão de poderes e micropoderes que se apresentam num processo aparentemente global. 
As respostas dos distintos sujeitos às exigências externas somam-se às preocupações com a eficiência do seu trabalho, segundo as expectativas de agentes externos em diferentes níveis. Como conseqüência, cada um procura formas de obter sucesso e garantir a competitividade dos seus empreendimentos. O conhecimento necessário para se atingir tais objetivos é construído num contexto anteriormente pouco explorado ou vivenciado por esses atores sociais. Nas novas situações a que são expostos, a tradição parece não ser de muita valia, embora, como indicam outros estudos, ela se apresente com nova roupagem nos novos contextos.

A definição de um padrão de qualidade a ser atingido pressupõe, por outro lado, a delimitação de áreas de saber, saber esse que é passível de transmissão. Assim, há mudanças nas trajetórias individuais que decorrem do modo pelo qual cada um se insere no novo contexto ou adquire novos habitus de como lidar com situações emergentes.

\section{À guisa de conclusão}

Para ilustrar a análise feita, foram selecionados alguns casos que apresentam situações vividas por alguns de nossos informantes (os nomes são fictícios), nas quais demonstram suas preocupações e o tipo de estratégias que utilizam para responder aos desafios dos mercados. Seus relatos indicam uma história recente de ligação com a fruticultura, não mais do que 12 anos de atividade, mas são exemplares no sentido de demonstrar as relações que cada um dos produtores estabelece com os mercados, adquirindo maior expressão no caso das grandes empresas mais vinculadas aos mercados externos.

Hisamura, 30 anos, solteiro, chegou a Petrolina no fim do ano de 1991, convidado pelo pai, de origem japonesa, que havia adquirido na região dois lotes para o plantio de manga. À época Hisamura, que se encontrava há dois anos no Japão trabalhando em fábrica de peças, foi chamado de volta pelo pai, pois as mangas estavam em tempo de colheita e "ele veio para cá ajudar".

Dos 24 ha, 23 eram cultivados, distribuídos em cultivos intercalados: manga, acerola, pinha, coco, uva. Os lotes são administrados pelo pai e pelo filho; a área de viticultura está arrendada a outro produtor, que paga $20 \%$ do lucro obtido ao japonês. Este fala sobre o trabalho realizado por homens e mulheres nos seus lotes, sobre a supervisão que recebe de um agrônomo e sobre a sua inserção na agricultura; narra o que aprendeu: "foi nesses três anos, ainda não entendo muito, porque não tinha costume de roça". Entre seu aprendizado, cita:

- conseguir produção fora do tempo é mais lucrativo; no caso da manga por exemplo, o preço só é bom quando há escassez no mercado: “A gente não sabe direito como fazer"; 
- "tem um tempo certo para fazer a indução e a irrigação, tem que controlar tudo";

- é necessário conhecer a agricultura. Se não, como seria possível exigir um trabalho especializado dos trabalhadores, quando ele próprio - $\mathrm{O}$ produtor - não sabe? " $O$ trabalhador, do jeito que a gente pede ele faz, mas a gente não sabe como conseguir";

- na relação dos produtores com as empresas que compram a sua produção, tomando como exemplo o contrato com a Nicherei para produzir acerola, ele afirma que o contrato é feito com a empresa, que lhe forneceu as mudas. "Eles fornecem a muda e a gente é obrigado a fornecer a produção prá eles. Eles definem uma quantidade limite, por peso; depois desse limite eles não têm mais obrigação de comprar a produção". Assim, os produtores devem ter compradores particulares. "Eles vêm comprar nos lotes e vendem prá fora". As vendas para o mercado local ou regional são de produtos que excederam as possibilidades de venda às cooperativas e às empresas, uma mistura de produtos, incluindo pinha e coco;

- pagar o salário mínimo definido para o setor é mais vantajoso para os produtores; anteriormente, trabalhando por produção, os trabalhadores eram melhor remunerados; portanto, ele tem todos os seus trabalhadores registrados e recebendo o salário da categoria.

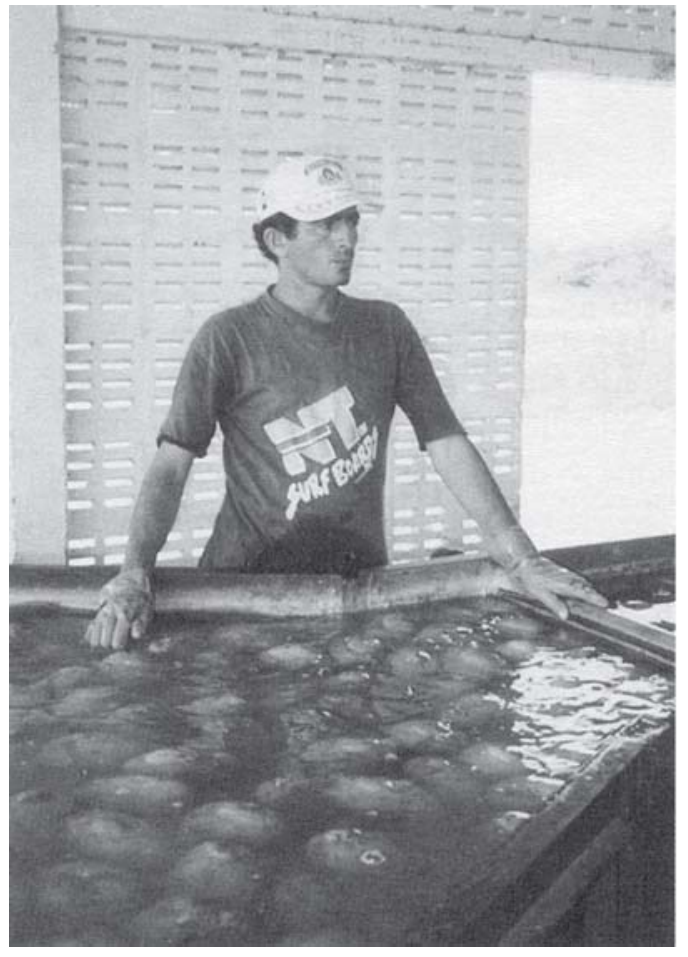

Controle de qualidade da manga

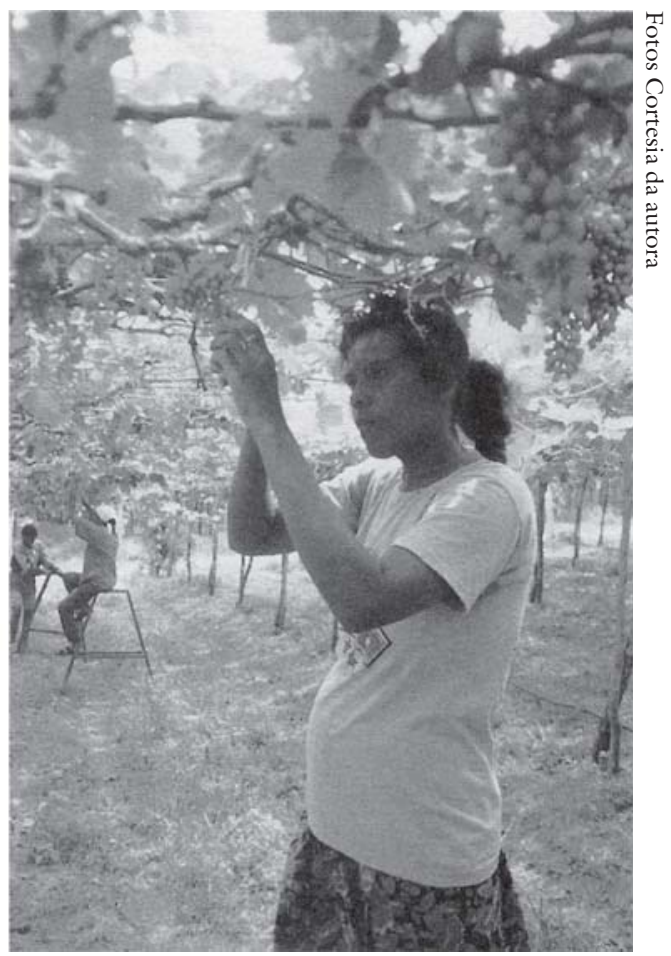

Colheita da uva 
José é um pequeno empresário de 43 anos, casado, pai de três filhos com dois, seis e sete anos de idade. Possui 18 ha de terra onde cultiva uva, goiaba, mamão, entre outras frutas. Foi empregado assalariado em agroindústria, até conseguir se estabelecer como produtor. Sua mulher também trabalha, fazendo os serviços externos aos lotes como pagamentos a bancos etc. Alfabetizado após os 30 anos de idade, ele conseguiu concluir o curso superior de administração e vem desenvolvendo em seus lotes um programa de qualidade total: "é a primeira empresa que fez um programa de relações humanas na área”. Segundo sua informação, no futuro quer tornar seus empregados em parceiros. Torná-los sócios dentro da empresa "é o risco que se tem que correr". Para ele, os aspectos importantes da gestão dos seus lotes são:

- exigir trabalho dos funcionários;

- atender bem aos clientes; ter mais de um cliente; nunca vender mais do que $70 \%$ da produção a um só cliente;

- estar bem informado; para isso participa de três associações: Valexport, Câmara da Uva e Associação dos pequenos produtores de qualidade, esta última recentemente desativada.

Tal estratégia, segundo sua apreciação, permite-lhe "conhecer por antecipação as novidades para o setor; preços, mercados, novas variedades de uva". Em suas palavras: "Quem sabe mais tem mais sorte... As empresas que conhecem o outro lado se organizam melhor... No mundo existem regras que beneficiam essas macroestruturas... e os pequenos têm que fazer o possível para não ser engolidos".

João, 48 anos, é diretor de uma empresa produtora e exportadora. A empresa está funcionando há 12 anos, tem 250 trabalhadores diretos e contrata mais 300 no período de safra. Tendo experimentado vários cultivos, entre eles limão, tomate, melão e manga, comparou a rentabilidade de cada um, realizou estudo de mercados, optando finalmente pela produção de manga e uva. Na atualidade a empresa cultiva 400 ha de manga e 10 ha de uva e pretende ampliar a viticultura para 120 ha. A decisão foi tomada após três anos de pesquisa. Exporta 90\% da produção de mangas para a Europa. Além dos estudos de mercado e pesquisas comparativas, a empresa adota as seguintes estratégias de marketing:

- contatos no exterior: mantém funcionários na Europa e nos Estados Unidos para acompanhar os mercados, fazer pesquisa de preços e oferecer à empresa as informações requeridas;

- propaganda: exporta com o rótulo da própria empresa e faz propaganda em revistas especializadas em frutas; 
- procura informações sobre a produção em outros países;

- lê o jornal Gazeta Mercantil para acompanhar os preços no mercado interno;

- possui uma packing house com três câmaras frigoríficas e adquiriu carretas-baú frigorífica para transportar as frutas até o porto;

- mantém equipes bem treinadas e um ótimo programa de reciclagem; os agrônomos viajam para outros países fruticultores objetivando obter maiores informações sobre novas variedades de uva, por exemplo.

Os casos apresentados revelam os múltiplos mecanismos utilizados para tornar a produção do vale competitiva no mercado global. A tais mecanismos somam-se as características climáticas da região, o preço da mão-de-obra - em torno de $\$ 0.75$ a hora -, a possibilidade de indução da produção de manga e de duas safras e meia de uva por ano, não obstante os desgastes ambientais que se insinuam. As estratégias usadas pelos seus atores sociais tendem a minimizar os obstáculos que se interpõem ao desenvolvimento da região e a maximizar as oportunidades que se apresentam, num jogo de forças.

Quadro 1

Frutas exportadas

\begin{tabular}{|ccr|}
\hline Ano & Manga $(\mathrm{t})$ & Uva $(\mathrm{t})$ \\
\hline 1991 & 3.000 & 1.050 \\
1992 & 9.000 & 5.000 \\
1993 & 13.000 & 10.000 \\
1994 & 18.000 & 14.000 \\
1995 & 20.000 & 12.500 \\
$1996^{*}$ & 23.000 & 15.000 \\
\hline
\end{tabular}

* Previsão a ser confirmada.

Fonte: Codevasf (1995/1996) e Valexport

Quadro 2

Produção e exportação de frutas

\begin{tabular}{|ccccccc|}
\hline Ano & \multicolumn{3}{c}{ Uva } & \multicolumn{2}{c|}{ Manga } \\
& $\begin{array}{c}\text { Área em } \\
\text { Produção } \\
\text { (ha) }\end{array}$ & $\begin{array}{c}\text { Quant. } \\
\text { Produzida }\end{array}$ & $\begin{array}{c}\text { Exporta- } \\
\text { ção } \\
(\mathrm{t})\end{array}$ & $\begin{array}{c}\text { Área em } \\
\text { Produção } \\
(\text { ha) }\end{array}$ & $\begin{array}{c}\text { Quant. } \\
\text { Produzida } \\
(\mathrm{t})\end{array}$ & $\begin{array}{c}\text { Exporta- } \\
\text { ção } \\
(\mathrm{t})\end{array}$ \\
\hline 1991 & 2.300 & 32.000 & 1.050 & 1.150 & 8.800 & 3.000 \\
1992 & 2.500 & 40.000 & 5.000 & 1.900 & 12.000 & 9.000 \\
1993 & 3.000 & 52.000 & 10.000 & 2.650 & 25.000 & 13.000 \\
1994 & 3.500 & 94.500 & 14.000 & 3.600 & 35.000 & 18.000 \\
1995 & 4.000 & 110.000 & 12.500 & 4.500 & 43.000 & 20.000 \\
\hline
\end{tabular}

Fonte: Valexport, 1996. 
Referências bibliográficas

ARAÚJO, Tânia Barcelar de. Nordeste, nordestes: que Nordeste? In: AFFONSO, Rui de Britto Álvares (ed.). Desigualdades regionais e desenvolvimento. São Paulo, Fundap, 1995. Federalismo no Brasil, p. 125-156.

BENDINI, Mônica \& CAVALCANTI, Josefa Salete Barbosa. Globalization and labor in Argentinean and Brazilian fruitculture regions: a comparative analysis. Recife, 1996. Trabalho apresentado no 9th World Congress of Rural Sociology, Romênia, 1996.

BLOCH, Didier. As frutas amargas do velho Chico: irrigação e desenvolvimento no vale do São Francisco. São Paulo, Livros da Terra, Oxfam, 1996. 117 p.

BONANNO, Alessandro et al. (eds.). From Columbus to Conagra: the globalization of agriculture and food. Lawrence, Uniersity of Kansas, 1994. 294 p.

BRASIL. Senado Federal. Relatório especial para o desenvolvimento do vale do São Francisco, v. 1. Brasília, 1995. 178 p.

CAVALCANTI, Josefa Salete Barbosa. Globalização, urbanização e reprodução da força de trabalho. In: MAGALHÃES, Sônia B. et al. (orgs.). Energia na Amazônia: grandes obras hidrelétricas: urbanização, constituição e reprodução da força de trabalho. Belém, Museu Paraense Emílio Goeldi/UFBA/Associação de Universidades Amazônicas, 1996, p. 421-429.

Globalização e agricultura: processos sociais e perspectivas teóricas. Estudos de Sociologia, revista do Programa de Pós-Graduação em Sociologia da UFPE, v. 1, n. 2, p. 105-118, jul./dez. 1995.

CAVALCANTI, Josefa Salete Barbosa \& FERREIRA IRMÃO, José. Globalização, integração regional e seus impactos sobre a agricultura familiar: um estudo sobre os sistemas de produção do vale do São Francisco, Nordeste-Brasil. In: Encontro Nacional do Pipsa, 17, Anais, 1994. Porto Alegre, UfRGS, 1995, v. 1, p. 59-72.

CAVALCANTI, Josefa Salete Barbosa; RAMOS, Juliana Vilar R. \& SILVA, Ana Cristina. B. da. Mulher e trabalho na fruticultura de exportação: as trabalhadoras na viticultura no Nordeste brasileiro. Trabalho apresentado ao II Congresso Latino Americano de Sociologia do Trabalho. Águas de Lindóia-SP, 1-5 dez. 1996 [publicado em resumos].

CODEVASF. $3^{\text {a }}$ Superintendência Regional. Relatório $1^{0}$ semestre 1996: informações técnicas. Petrolina, Codevasf, 1996. $37 \mathrm{p}$.

FRIEDLAND, William $\mathrm{H}$. The new globalization: the case of fresh produce. In: BONANNO, Alessandro et al. (eds.). From Columbus to Conagra: the globalization of agriculture and food. Lawrence, University of Kansas, 1994, p. 210-231. 294 p. (Rural America).

LIMA, Policarpo. Economia do Nordeste: tendências recentes das áreas dinâmicas. Recife, 1994 [textos para discussão, PIMES-UFPE].

MARSDEN, Terry K. \& ARCE, A. Constructing quality: emerging food networks in the rural transition. Environment and Planning A, v. 27, 1995. 
MARSDEN, Terry K.; CAVALCANTI, Josefa Salete Barbosa \& FERREIRA IRMÃO, José. Globalization, regionalisation and quality: the socio-economic reconstitution of food in the San Francisco valley, Brazil. International Journal of Sociology and Food, Pullman, v. 5, p. 85-114.

MENDEL R., Julia et al. Las temporeras y su visión del trabajo. Santiago, Centro de Estudios de la Mujer, 1989.

MICHIE, Jonathan \& SMITH, John Grieve. Managing the global economy. Oxford, Oxford University, 1995.

SABEL, Charles F. Flexible specialisation and the re-emergence of regional economies. In: AMIN, Ash (ed.). Post-fordism: a reader. Oxford, Blackwell, 1994, p. 101-156.

SPYBEY, Tony. The producer-consumer in the global economy. In: Globalization and world society. Oxford, Blackwell, 1996, p. 75-13.

UFPE. PIMES. Impactos econômicos da irrigação sobre o polo Petrolina Juazeiro. Recife, Editora Universitária da UFPE, 1991.

VERGOLINO, Tercina B. O. \& VERGOLINO, José Raimundo de O. Relações de trabalho e condições de vida dos trabalhadores na agricultura irrigada do submédio São Francisco: relatório final. Recife, Facepe: UFPE/PIMES, 1995. 139 p.

Josefa Salete Barbosa Cavalcanti é professora do Departamento de Ciências Sociais da UfPE (Programa de Pós-Graduação em Sociologia e Mestrado em Antropologia), pesquisadora do CNPq e Ph.D em Sociologia pela Universidade de Manchester (EUA). 